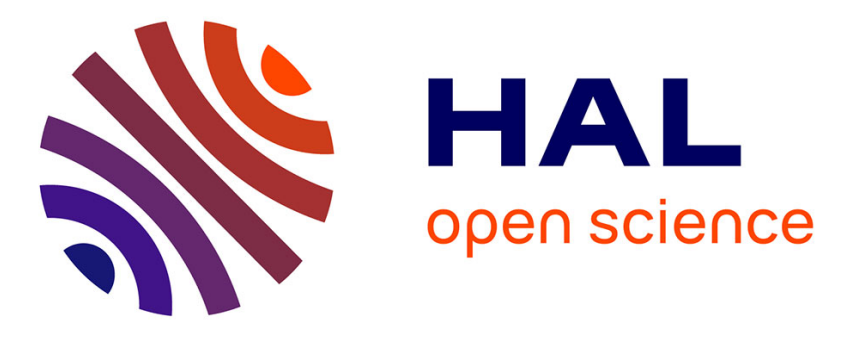

\title{
A rapid scatter prediction method for very high cycle fatigue
}

Zhi Yong Huang, Qing Yuan Wang, Danièle Wagner, Claude Bathias, Jean

Louis Chaboche

\section{- To cite this version:}

Zhi Yong Huang, Qing Yuan Wang, Danièle Wagner, Claude Bathias, Jean Louis Chaboche. A rapid scatter prediction method for very high cycle fatigue. Fatigue and Fracture of Engineering Materials and Structures, 2013, 36 (5), pp.462-468. 10.1111/ffe.12021 . hal-01686407

\section{HAL Id: hal-01686407 https://hal.parisnanterre.fr/hal-01686407}

Submitted on 22 Jan 2018

HAL is a multi-disciplinary open access archive for the deposit and dissemination of scientific research documents, whether they are published or not. The documents may come from teaching and research institutions in France or abroad, or from public or private research centers.
L'archive ouverte pluridisciplinaire HAL, est destinée au dépôt et à la diffusion de documents scientifiques de niveau recherche, publiés ou non, émanant des établissements d'enseignement et de recherche français ou étrangers, des laboratoires publics ou privés. 


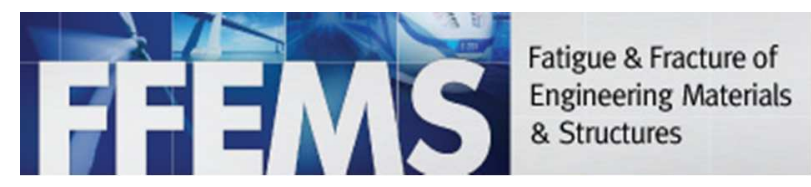

\section{A rapid scatter prediction method for Very High Cycle Fatigue}

\begin{tabular}{|r|l|}
\hline Journal: & Fatigue and Fracture of Engineering Materials and Structures \\
\hline Manuscript ID: & FFEMS-5081 \\
\hline Manuscript Type: & Original Contribution \\
\hline Date Submitted by the Author: & 13 -Jun-2012 \\
\hline Complete List of Authors: & $\begin{array}{l}\text { HUANG, Zhiyong; Sichuan University, College of architecture and } \\
\text { environment } \\
\text { Wang, Qingyuan; Sichuan University, ; } \\
\text { WAGNER, Daniele; University Paris X, ENSAM, } \\
\text { Bathias, Claude; University of Paris, LEEE/ITMA }\end{array}$ \\
\hline Keywords: & Damage mechanics, Very high-cycle fatigue \\
\hline &
\end{tabular}

SCHOLARONE ${ }^{m}$

Manuscripts 


\title{
A rapid scatter prediction method for Very High
}

\section{Cycle Fatigue}

\author{
Zhi Yong Huang ${ }^{1)}$, Qing Yuan Wang ${ }^{1)}$, Danièle Wagner ${ }^{2)}$, Claude Bathias ${ }^{2)}$, Jean Louis-Chaboche ${ }^{3)}$ \\ 1) Sichuan University, China \\ 2)Université ParisOuest Nanterre La Défense, France
}

3) ONERA,France

\begin{abstract}
VHCF tests are often performed by a high frequency fatigue test system, such as ultrasonic fatigue test machine. In the article, simple VHCF tests and cumulative fatigue (LCF plus VHCF) tests are performed to investigate the fatigue behavior respectively for a low carbon manganese steel. The test results in Wöhler diagram show a large scatter in VHCF regime. Continuum Damage Mechanics model is extended to VHCF region to estimate the remaining fatigue life. A rapid fatigue failure probability prediction method is applied and extended to VHCF regime in order to evaluate the fatigue dispersion based on multi scales model and fatigue dissipation analysis.
\end{abstract}

\section{KEYWORDS:}

Very High Cycle Fatigue; Cumulative fatigue; Thermal dissipation; Fatigue dispersion

\section{Introduction}

In PWR (Pressurized Water Reactor), high pressure water transfers energy via the primary loop into steam generator. The loop pipes connected to the steam generator were designed to withstand the internal pressure. But previous research [1] shows that the pipes are also sustained long time repeated stratified alternation loads due to the injection of cold water. 
Fluctuations of the interface in the pipes between cold and hot fluids are due to series of activation of the emergency feed water lines connected to the main ones. Injection of emergency cold water induces cyclic stress and affects the fatigue life of the material.

The long time repeated alternation loads due to cold water injection is thought as very high cycle fatigue (VHCF) damage. The thermo hydraulic load that appears suddenly during the injection of cold water (from the backup supply) into the feedwater lines is regarded as low cycle fatigue (LCF) load. In PWR, some pipes connected to the steam generator are made in Carbon Manganese steel.

The component design needs test data and mechanical theory to ensure the reliability. The VHCF tests up to $10^{9}$ cycles are necessary and often implemented on a high frequency fatigue machine like ultrasonic fatigue machine to accelerate the test process [2].

Continuum Damage Mechanics (CDM) theory, gives out a theoretical preparation to evaluate fatigue damage and to predict the remaining life, which is originally proposed by Kachanov [3] and Rabotnov [4], and improved by Lemaitre [5], Chaboche [6], Chow and Wang [7], Murakami [8]. The non linear cumulative damage rule based on the theory is successfully used to evaluate the prior fatigue damage effects on the subsequence fatigue life in the case of two level fatigue load [9].

Fatigue data is usually scattered, so probabilistic methods has been applied to describe it [10]. Identification of the model is normally based on the numerous experimental fatigue test results. Defects like inclusions, voids, etc. distributed in the material randomly turn into the crack initiation source under fatigue loads. The quantity, size and distribution of the defects are statistically investigated to evaluate the reliability of structure [11].

Fatigue failure happens after $10^{7}$ cycles in terms of the reports [2,9]. The dispersion of fatigue life is important and the crack initiation competition appears between the surface flaws and the subsurface defects in VHCF regime [2].

Ultrasonic fatigue test machine is often used to perform the VHCF and provides a high frequency $(20 \mathrm{kHz})$ to accelerate the fatigue test, but the fatigue thermal dissipation is also 
significant through the observation of infrared camera [12]. Self heating phenomenon in fatigue is a complicated thermo - mechanical process. Intrinsic fatigue dissipation is closely associated with a set of sites which has micro plastic deformation activated by high frequency cyclic load. The local anelastic or inelastic deformation appears in the grains with certain orientations or the material defects surrounded by elastic matrix [13]. Fatigue dissipation test is used to estimate the number or the volume of the active sites [14]. Temperature increment after fatigue cyclic stabilization at different loads is applied to analysis the thermal dissipation. A correlation between the load level and temperature increasing for a material has been empirical proposed based on the self heating measurement.

The present study focuses on developing a model to predict the VHCF dispersion by its intrinsic fatigue dissipation observation in high frequency fatigue test condition under the assumption that micro inelastic deformation randomly occurs at the grains or the defects obeying the well known Poisson Point Process. It is also applied to the case of cumulative fatigue for a low carbon manganese steel.

\section{Material and specimen}

The investigated material is a kind of $\mathrm{C}-\mathrm{Mn}$ steel A42 received as $40 \mathrm{~mm}$ thick plates. The chemical compositions and mechanical characters of the material are given in table 1 and table 2. The plates were submitted to a prior normalization heat treatment at $870^{\circ} \mathrm{C}$ followed by air cooling.

The material is a ferrite - pearlite dual phase steel. The structure takes the form of alternating bands of ferrite and pearlite (Fig.1) because of segregated minor inter-dendritic elements (mainly manganese). In the rich areas of manganese, the eutectoid reaction is slowed, and the pearlite is formed mainly in low manganese areas, where the micro structure appears alternating bands of pearlite and ferrite.

In order to perform the tests up to $10^{9}$ cycles in a reasonable time, the ultrasonic fatigue test machine is applied with $20 \mathrm{kHz}$ frequency. A axi symmetric form specimen in geometry is 
designed as Fig.2 shown.

\section{Fatigue tests}

The VHCF and cumulative fatigue tests have been performed in previous works [9]. A ultrasonic fatigue test machine was used to study the VHCF behavior with compressed air cooling. The process of cumulative fatigue is VHCF test following LCF test. For LCF load, the specimens were tested in uni-axial reversed strain load and controlled by transverse extensometer in a conventional hydraulic fatigue machine (Instron 8500).

The test results of VHCF and cumulative fatigue ( $\mathrm{LCF}+\mathrm{VHCF})$ are plotted in Fig 3 by square and round points respectively. In order to investigate the effect of LCF load on VHCF strength for the steel, the specimens (Fig.2), predamaged by LCF load (0.62\% strain amplitude, 100 cycles) (Fig 3) are used. The experimental results are shown in Fig 3 where the VHCF strength after LCF damaged presents a significant reducing.

Infrared camera is applied to measure the surface temperature of specimen during the ultrasonic fatigue test. The spectral range of the camera is near the infrared domain (the wavelength is between $3.7 \mu \mathrm{m}$ and $4.8 \mu \mathrm{m})$. Before the tests, the camera has been calibrated by a black body in a temperature range $20-200^{\circ} \mathrm{C}$. A specimen has been coated with strong emissive and high temperature resistance black paint (in this case, the emissivity coefficient can be regarded as 1). The ultrasonic fatigue temperature evolution at $160 \mathrm{MPa}$ stress amplitude $(R=-1)$ for the steel is recorded by infrared camera (Fig.4), and the average incremental temperature at cyclic stable stage is identified as Fig.4 shown. The corresponding self heating temperature in the stage under certain loads in ultrasonic fatigue tests and plotted in Fig.5.

\section{VHCF model}

The S-N curve of simple VHCF in uni axial test condition can be described by Basquin model [15] with a "pseudo-fatigue limit" [16]. The fatigue strength at $10^{9}$ or $10^{10}$ cycles with certain probability could be substituted by the fatigue limit at $P_{F}$ (failure probability): 
$N_{f}\left(\Sigma_{a}, P_{F}\right)=\left(\frac{\Sigma_{a}-\Sigma_{D}\left(P_{F}\right)}{M}\right)^{-\gamma}$

Where, $\Sigma_{D}\left(P_{F}\right)$ is the fatigue strength at $10^{9}$ cycles and parameter $P_{F}$ is fatigue failure possibility. The parameter $M$ and exponent $\gamma$ are both Basquin parameters depending on material.

\subsection{Two Level cumulative damage model}

One of the differential forms of two level cumulative fatigue damage models is used here and is written as damage rate (by cycle) expression:

$$
\frac{d D}{d N}=\frac{D^{\alpha}}{(1-\alpha) F\left(\Sigma_{a}\right)}
$$

And

$$
\frac{d D}{d N}=\frac{D^{\alpha}}{G\left(\Sigma_{a}\right)}
$$

$\mathrm{F}$ is the function to describe the S-N curve when the stress amplitude is higher than "fatigue limit". G is the "hidden function" proposed by Chaboche [16] to estimate the damage when the load is lower than the "fatigue limit".

The scatter of fatigue strength is important from the observation of test results (Fig. 3) and the failure probability is necessary to be introduced into the model. In LCF, HCF, VHCF regime, F function could be expressed as follows:

$$
F\left(\Sigma_{a i}, P_{F}\right)=N_{f i}\left(\Sigma_{a i}, P_{F}\right)=\left(\frac{\Sigma_{a i}-\Sigma_{D i}\left(P_{F}\right)}{M_{i}}\right)^{-\gamma_{i}} \quad(\mathrm{i}=1,2)
$$

Where, $\mathrm{i}=1$, 2, 3 means LCF, HCF, VHCF regime respectively. In VHCF regime, the fatigue strength is below "fatigue limit" $\Sigma_{D 1}$ because it continuously declines with the number of cycles increasing, especially in the case of cumulative fatigue.

And the $\mathrm{G}$ function can be expressed with probability as: 
$G\left(\Sigma_{a i}, P_{F}\right)=N_{f i}^{*}\left(\Sigma_{a i}, P_{F}\right)=\left(\frac{\Sigma_{a i}-\Sigma_{D i}^{*}\left(P_{F}\right)}{M_{i}^{*}}\right)^{-\beta_{i}^{*}} \quad(\mathrm{i}=1,2,3)$

Where, $\quad \beta^{*}{ }_{i}=\theta_{i} \gamma_{i}, \quad \theta_{i} \quad(i=1,2,3)$ is the additional parameters. Subscript $i=1,2,3$ indicates LCF, HCF, VHCF domain respectively [9]. If the cumulative test is only in one regime with two different stress level, the S-N curve function and hidden function $N_{f i}^{*}\left(\Sigma_{a i}\right)$ are both degraded to Chaboche's accumulated fatigue damage model. Equality of both sides of equation (2), (3) the function $\alpha$ is obtained.

In the case of two level loads, the fatigue life can be predicted at second load level by following equation (6) under the VHCF cyclic loading.

$n_{2}=N_{f_{2}}\left[1-\left(\frac{n_{1}}{N_{f_{1}}}\right)^{\frac{1-\alpha_{2}}{1-\alpha_{1}}}\right]$

Where, $\alpha_{1}$ and $\alpha_{2}$ are the values of the function $\alpha$ at the two levels. The exponent is determined by:

$\frac{1-\alpha_{2}}{1-\alpha_{1}}=\frac{N_{f_{1}}}{N_{f_{2}}} \frac{N_{f_{2}}^{*}}{N_{f_{1}}^{*}}$

\subsection{Self heating model in VHCF}

The active sites with micro inelastic deformation under fatigue load are supposed to be located at certain grains or defects of material in terms of fatigue failure mechanism [2]. The self heating is due to the dissipation of micro deformation energy at the sites and the number is variable according to the level of cyclic fatigue load. The active sites could be grains with certain orientations or material defects like non metallic inclusions, surrounded by elastic matrix randomly distributed in the material and aroused by cyclic load in macroscope. These sites are considered to follow a power law with stress amplitude $\Sigma_{a}$ in a representative 
volume element (RVE) [14] with an assumption that the microscopic yield stress is a probabilistic variable.

$$
\lambda\left(\Sigma_{a}\right)=\frac{1}{V_{0}}\left(\frac{\Sigma_{a}}{S_{0}}\right)^{m}
$$

$\lambda$ is intensity of activated sites under load $\Sigma_{a}$. Average volume of each site is denoted by $V_{0}$. Parameters $S_{0}, m$ are parameters depending on the probability distribution of yield stress at the sites.

The probability $P_{K}$ of finding $k$ activated sites follows the Poisson distribution [17] in a domain of volume $V_{\Omega}$ where the average number of the potential sites is $\bar{n}_{a}$ at a given load:

$$
P_{K}(X=k)=\exp \left(-\bar{n}_{a}\right) \frac{\left(\bar{n}_{a}\right)^{k}}{k !}
$$

Where, $\bar{n}_{a}$ is the number of average active sites and is given by:

$$
\bar{n}_{a}=\lambda\left(\Sigma_{a}\right) V_{\Omega}
$$

Failure probability $P_{F}$ is thought that at least one active site appearance in the studying volume leads to the failure of specimen.

$$
P_{F}=P_{K}(X \geq 1)=1-P_{K}(X=0)
$$

Referring the equation (9), the equation (11) can be rewritten by:

$$
P_{F}=1-\exp \left[-\frac{V_{\Omega}}{V_{0}}\left(\frac{\Sigma_{a}}{S_{0}}\right)^{m}\right]
$$

The failure probability follows Weibull distribution [18] based on the research of RVE through integration the Poisson Point Process for the sites.

The HCF life prediction is often characterized with the assumption of "fatigue limit". But in the case of VHCF, since the fatigue strength decreasing continuously with the number of cycles increasing until $10^{9}$ cycles, the "fatigue limit" is hard to be found in terms of the investigation of C.Bathias [2]. It could be replaced by the fatigue strength at $10^{9}$ cycles with $50 \%$ failure 
probability in this case.

The fatigue strength at $10^{9}$ cycles with different failure possibility can be deduced from the equation (12) and expressed explicitly as follows:

$$
\Sigma_{D}\left(P_{F}\right)=\Sigma_{D}(0.5)\left[\frac{\ln \left(1-P_{F}\right)}{\ln (1-0.5)}\right]^{1 / m}
$$

The predicted fatigue strength only depends on the shape parameter $\mathrm{m}$ of Weibull distribution if the mean fatigue strength has been determined with $50 \%$ probability from S-N curve up to $10^{9}$ cycles.

In ultrasonic fatigue test, the $20 \mathrm{kHz}$ frequency causes pronounced heating dissipation due to micro anelastic and inelastic deformation at the activated sites.

The fatigue thermal dissipation is significant from the observation of infrared camera even at the low stress amplitude (Fig.5). The curve of temperature versus macroscopic stress amplitude can be divided into 2 parts according to the rate of the temperature rise. The speed of temperature increasing at first part in Fig. 5 is lower relatively which is considered mainly due to the micro anelastic deformation energy dissipation. With the load rising, the quantity of the active sites is largely increased in the representative volume element (RVE) and the inelastic deformation dissipation at the sites seems to dominate the self heating process in the second part of the curve.

The thermal dissipation caused by inelastic deformation for a unit of the RVE can be estimated in term of the reference $[14,17]$ :

$d_{i n}=\frac{4 f_{v} \sigma_{y}}{h}\left(\Sigma_{0}-\sigma_{y}\right)$

Where, $\sigma_{y}$ is local cyclic yield stress of an active site. $h$ is hardening modulus and is expressed as $h=C+3 \mu(1-\beta)$, where $\mathrm{C}$ is proportionality parameter of a linear kinematic 
hardening law; $\beta=\frac{2(4-5 v)}{15(1-v)}$ is constant from Eshelby tensor [19]. $f_{v}$ is volume fraction for the total active sites. The number of incremental sites $d N_{a}$ is activated when the load is varying from $\Sigma$ to $\Sigma+d \Sigma$ in RVE with a volume $V_{\Omega}$.

$d N_{a}(\Sigma)=V_{\Omega} \frac{d \lambda}{d \Sigma} d \Sigma$

The total cyclic dissipation is considered to be equaled to the summation of associated dissipation with the different yield stress $\Sigma$ weighted by the number of sites in the volume $V_{\Omega}$.

$D_{i n}=\int_{0}^{\Sigma_{0}} V_{\Omega} d_{i n} \frac{d \lambda}{d \Sigma} d \Sigma$

Integration the equation (16), the intensity of cyclic dissipation at the amplitude of stress $\Sigma_{0}$

is:

$D_{i n}=\frac{4 m}{h(m+1)(m+2)} \frac{\sum_{0}^{m+2}}{S_{0}^{m}}$

$V_{0}$ is the total volume of the active sites.

The local heat conduction equation is applied here [20]:

$\dot{\theta}+\frac{\bar{\theta}}{\tau_{e q}}=\frac{f_{r} D_{i n}}{\rho c}$

The average temperature rising due to the inelastic deformation of the active sites is calculated with the help of two scales model of Eshelby [21] and the inelastic deformation dissipation estimation by:

$\Delta \bar{T}=\bar{\theta}=\frac{4 m f_{r} \tau_{e q}}{h \rho c(m+1)(m+2)} \frac{\sum_{a}^{m+2}}{S_{0}^{m}}$

$f_{r}$ is the load frequency. $\tau_{e q}$ is the characteristic time depended on the thermal conductivity 
conditions during the fatigue tests.

The equation (15) can be rewritten with a compact form from:

$\Delta \bar{T}=f_{v} \delta \sum_{a}^{m+2}$

$m$ is the shape parameter in Weibull distribution (Equ.12) which is determined by the test of fatigue dissipation.

\section{Identification and discussion}

In terms of the reference [9] and the test results shown in Fig 1, the parameters for the fatigue model (Equ.1) and cumulative fatigue damage model (Equ.2) has been determined as: $a=0.14, \mathrm{~B}=200, \beta=3.5, \sigma_{l_{0}}(0.5)=200 \mathrm{MPa}, \sigma_{u}=460 \mathrm{MPa}$. In VHCF, the value of $\theta_{3}$ is taken as 0.5 ; but for LCF effect on VHCF, the parameter $\theta_{1}$ is identified as 0.1 in terms of the test results.

The difficulty is to predict the scatter in VHCF. The temperature rising due to self heating in ultrasonic fatigue is observed by the infrared camera. In log-log plot (Fig.5), the relation between temperature and stress characters bilinear curves. In the first part of the fatigue dissipation curve, the temperature shows a low rising rate at low stress amplitude seems corresponding to the anelastic deformation dissipation in VHCF; however, the second stage of the curve with a higher increasing rate seems due to the inelastic deformation at the activated sites. The dispersion of VHCF depends on the exponent parameter m (Equ.12), which can be obtained from the slope of the curve (Equ.16). The parameter $\mathrm{m}$ is identified as 10.5 from the log-log curve in Fig.6.

The equation 1 and 6 are applied respectively to describe the fatigue behavior of the VHCF test and the cumulative fatigue test ( $\mathrm{LCF}+\mathrm{VHCF})$. The curves are also predicted with the failure probability 0.2 and 0.8 in Fig.7 and Fig.8. The Fig.7 shows that the VHCF scatter seems to be well predicted. The dispersion of VHCF strength after damaged by LCF is also 
given out in failure probability 0.2 and 0.8 in Fig.8. The dispersion range of cumulative fatigue seems to be slightly overestimated because the fatigue dissipation is measured by a non damaged specimen in ultrasonic fatigue test.

\section{Conclusions}

The article investigates the dispersion of the simple VHCF and cumulative fatigue for the low carbon manganese steel. The method based on two scales model with the help of the fatigue thermal dissipation analysis seems to be capable to estimate the dispersion of VHCF and cumulative fatigue rapidly.

\section{Acknowledgments}

The authors thank for AREVA (France) and National Natural Science Research Foundation of China to provide financial supporting (No.51101107).

\section{REFERENCES}

[1]Le Duff, J., A. Lehéricy, Y. Lefrançois A. Mendez,J. (2009) Effects of surface finish and LCF pre-damage on the HCF endurance limits of A 304L austenitic stainless steel. Deutscher Verband fur Materialforschung und prufung. e.V., 1023-1033.

[2] Bathias,C. Paris, P., C. (2005) Gigacycle fatigue in Mechanical practice. Marcel Dekker. New York.

[3] Kachanov, L., M. (1958) Time of the rupture process under creep conditions, TVZ Akad Nauk S.S.R. Otd Tech. Nauk. 8.

[4] Rabotnov,Y.,N. (1969) Creep problems in structural members, North Holland Publishing Comp.

[5]Lematire, J. Chaboche, J., L. (1990) Mechanics of Solid Materials. Cambridge University Press, Cambridge.

[6].Chaboche, J., L . (1987) Continuum damage mechanics: present state and future trends. 
Nucl. Eng. Des., 105, 19-33.

[7] Chow, C., L. Wang, J. (1987) An anisotropic theory of continuum damage mechanics for ductile fracture. Eng. Fract. Mech., 27, 546-558.

[8] Murakami, S. (1987) Anisotropic aspects of material damage and application of continuum damage mechanics. CISM Courses and Lectures No.295, eds D.Krajcinovic and J.Lemaitre. Spring, Wien, pp. 91-133.

[9] Huang, Zhi, Yong. Wagner, Danièl. Bathias, Claude. Chaboche, Jean, Louis. (2011) Cumulative fatigue damage in low cycle fatigue and gigacycle fatigue for low carbon-manganese steel. Int. J. Fatigue., 33 , 115-121.

[10] Delahay, Thomas. Palin-Luc, Thierry. (2006) Estimation of the fatigue strength distribution in high-cycle multiaxial fatigue taking into account the stress-strain gradient effect. Int. J. Fatigue., 28, 5-6, 474-484.

[11] Murakami, Y. Usuki, H. (1989) Quantitative evaluation of effects of non-metallic inclusions on fatigue strength of high strength steels. II: Fatigue limit evaluation based on statistics for extreme values of inclusion size Original Research Article. Int. J. Fatigue., 11, 5, 299-307

[12] Ranc, N. Wagner, D. Paris, P.C. (2008) Study of thermal effects associated with crack propagation during very high cycle fatigue tests Original Research Article. Acta. Mater., 56, 15, 4012-4021.

[13] Sabar, H. Berveiller, M. Favier, V. Berbenni, S. (2002) A new class of micro-macro models for elastic-viscoplastic heterogeneous materials, Int. J. Solids. Struct, 39, 3257-3276,.

[14] Doudard, Cédric. Calloch, Sylvain. Hild, François. Cugy, Philippe. Galtier, André. (2004) Identification of the scatter in high cycle fatigue from temperature measurements, $C . R$. Mecanique, 332, 795-801

[14] Doudard, C. Calloch, S. Cugy, P. Galtier, A. Hild, F. (2005) A probabilistic two-scale model for high-cycle fatigue life predictions. Fatigue. Fract. Engng. Mater. Struct, 28, 279-88. 
[15] Basquin,O.H. (1910) The exponential law of endurance tests. Proc. Of the American Society for Testing and Material. 10, 625-630.

[16]Chaboche, J., Kaminski, L., M. Kanoute, P. (2009) Extension and application of a non-linear fatigue damage accumulation rule for variable amplitude loading programs. Deutscher Verband fur Materialforschung und prufung e.V., 627-639.

[17] Ezannoa, A. Doudarda, C. Callocha, S. Millotb, T. Heuzéc, J.-L. (2010) Fast characterization of high-cycle fatigue properties of a cast copper-aluminum alloy by self-heating measurements under cyclic loadings, Procedia Engieering 2, 967-976.

[18] Weibull, W. (1951) A statistical distribution function of wide applicability. ASME. J. Appl. Mech,18,293-7.

[19] Eshelby, J. D. (1957) The determination of the elastic field of an ellipsoidal inclusion and related problems. Proc. R. Soc. London A 241, 376-396.

[20] Boulanger, T. Chrysochoos, A., Mabru, C., Galtier, A. (2004). Calorimetric analysis of dissipative and thermoelastic effects associated with the fatigue behavior of steels. Int. $J$. Faiguet. 26, 221-229. 


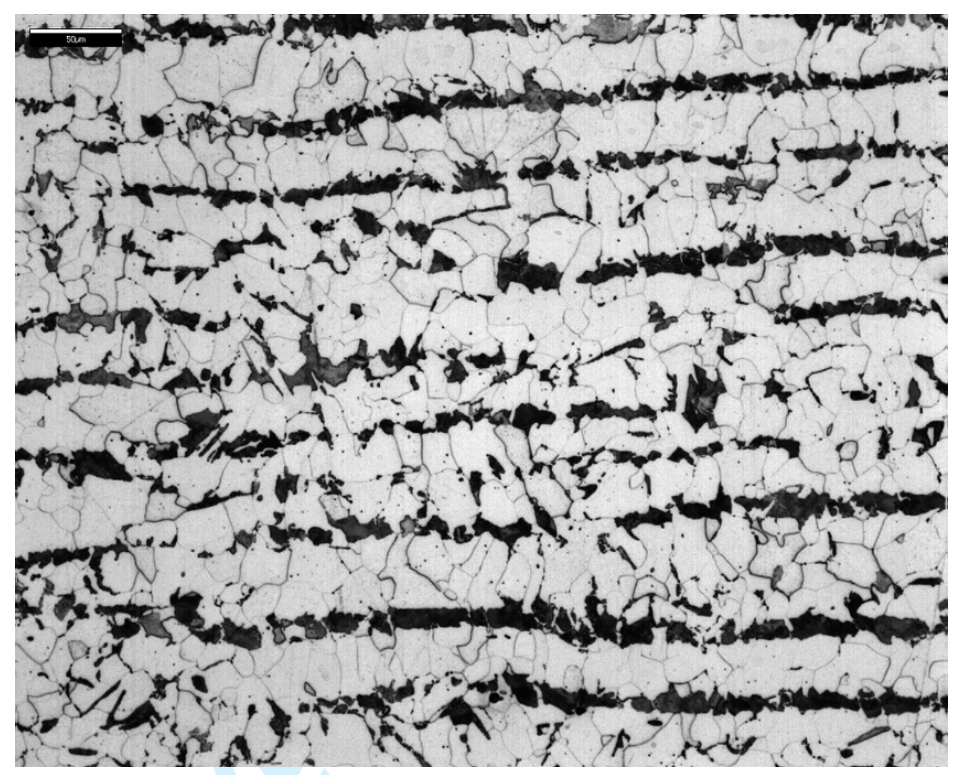

Figure 1 Microstructure of the steel A42 


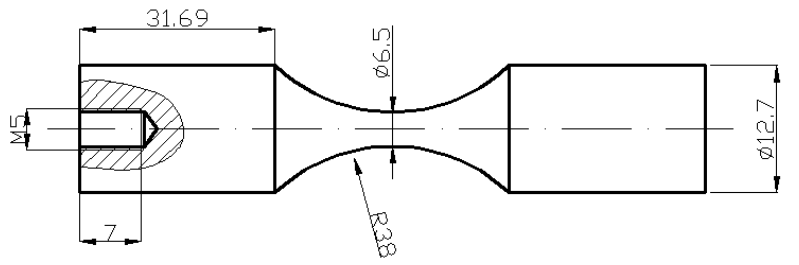

Figure 2 Specimen of VHCF 


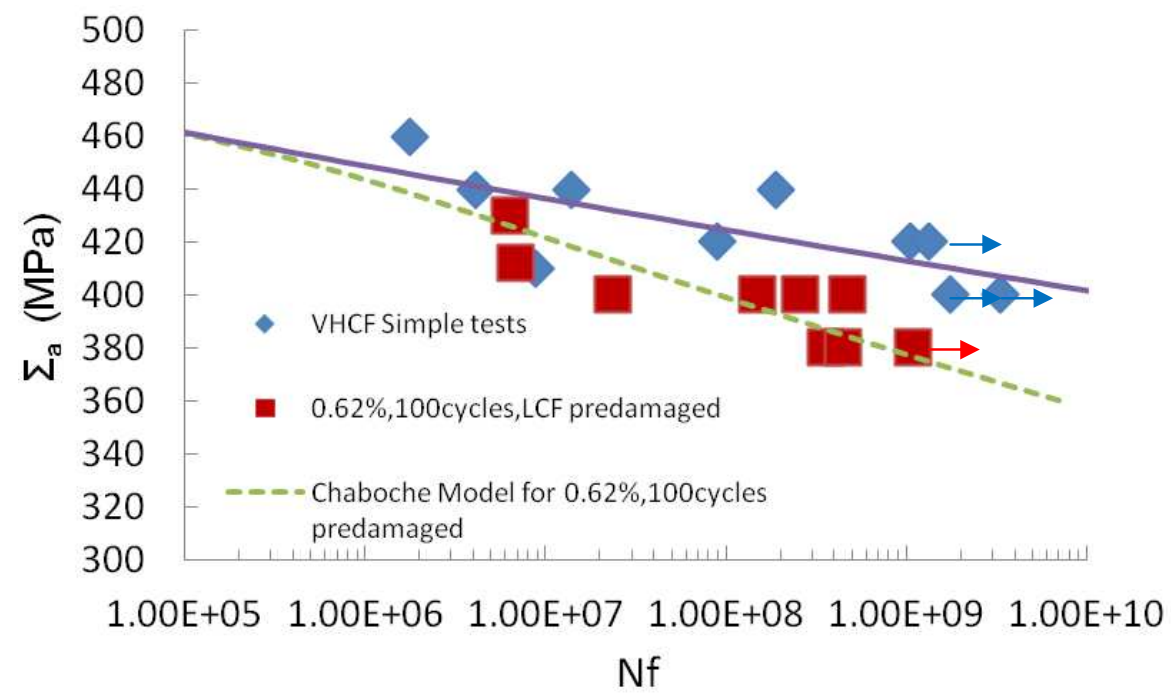

Figure 3 VHCF and Cumulative fatigue (LCF + VHCF) test results and estimation (Prior $0.62 \%$ strain amplitude, 100 cycles LCF damaged followed by VHCF ) 


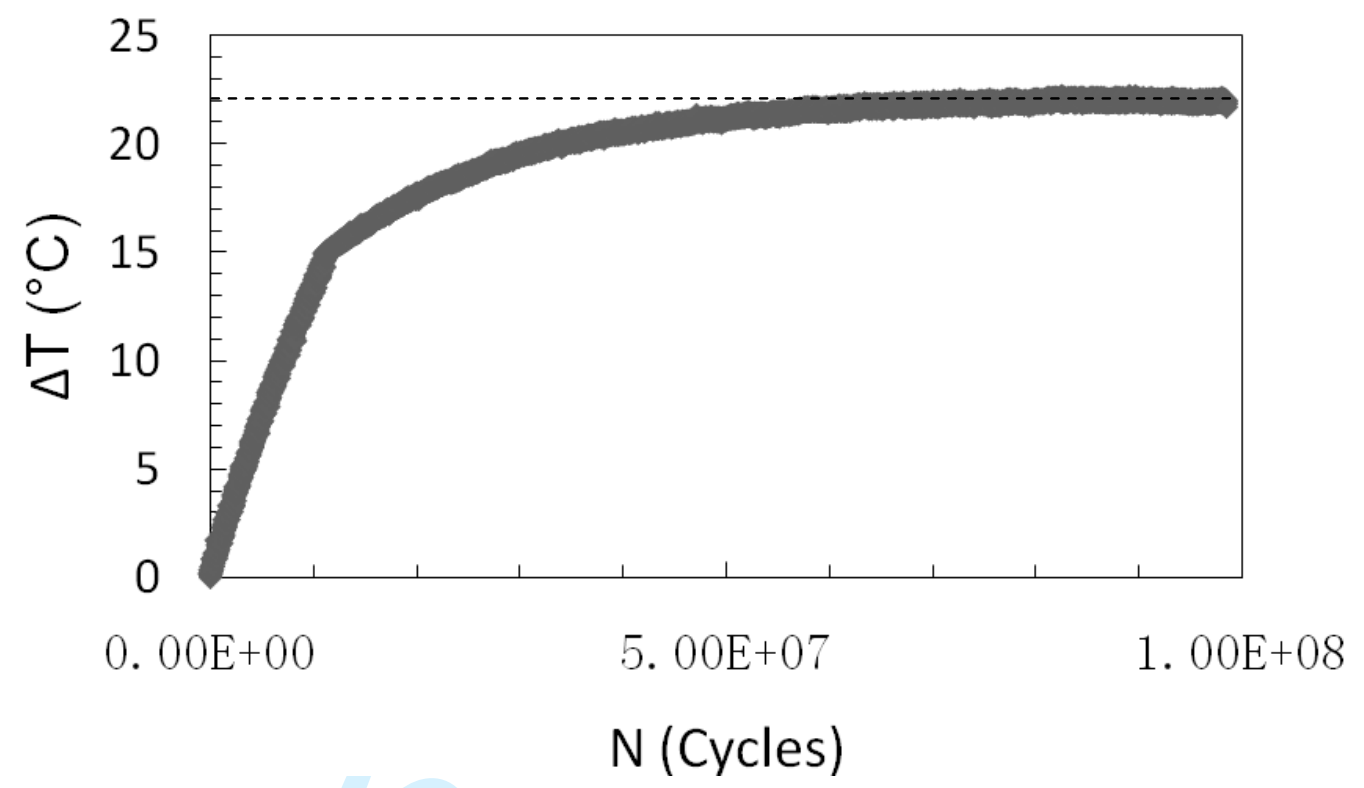

Figure 4 Self heating evolution in ultrasonic fatigue test (stress amplitude:160MPa, $\mathrm{R}=-1,20 \mathrm{kHz}, \mathrm{A} 42)$ 


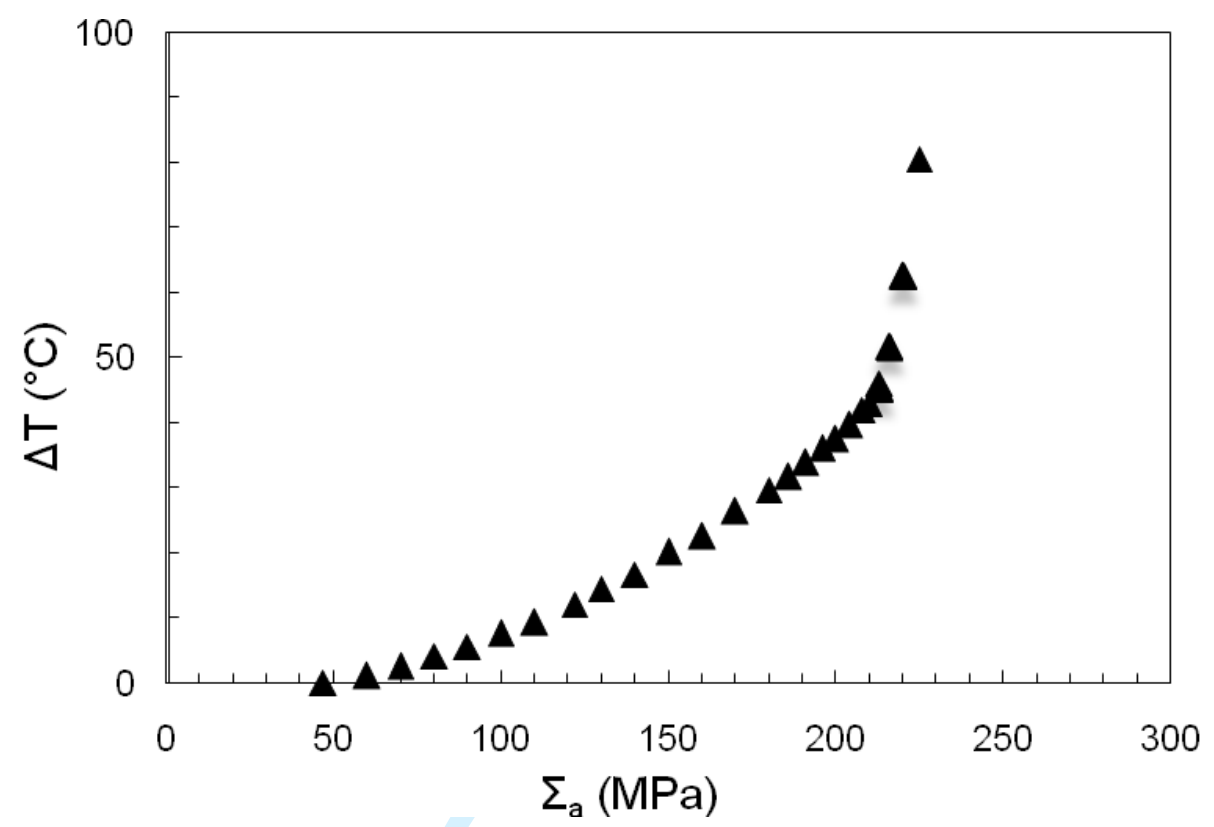

Figure 5 Incremental temperature at different macroscopic stress amplitudes in Ultrasonic fatigue tests for A42 


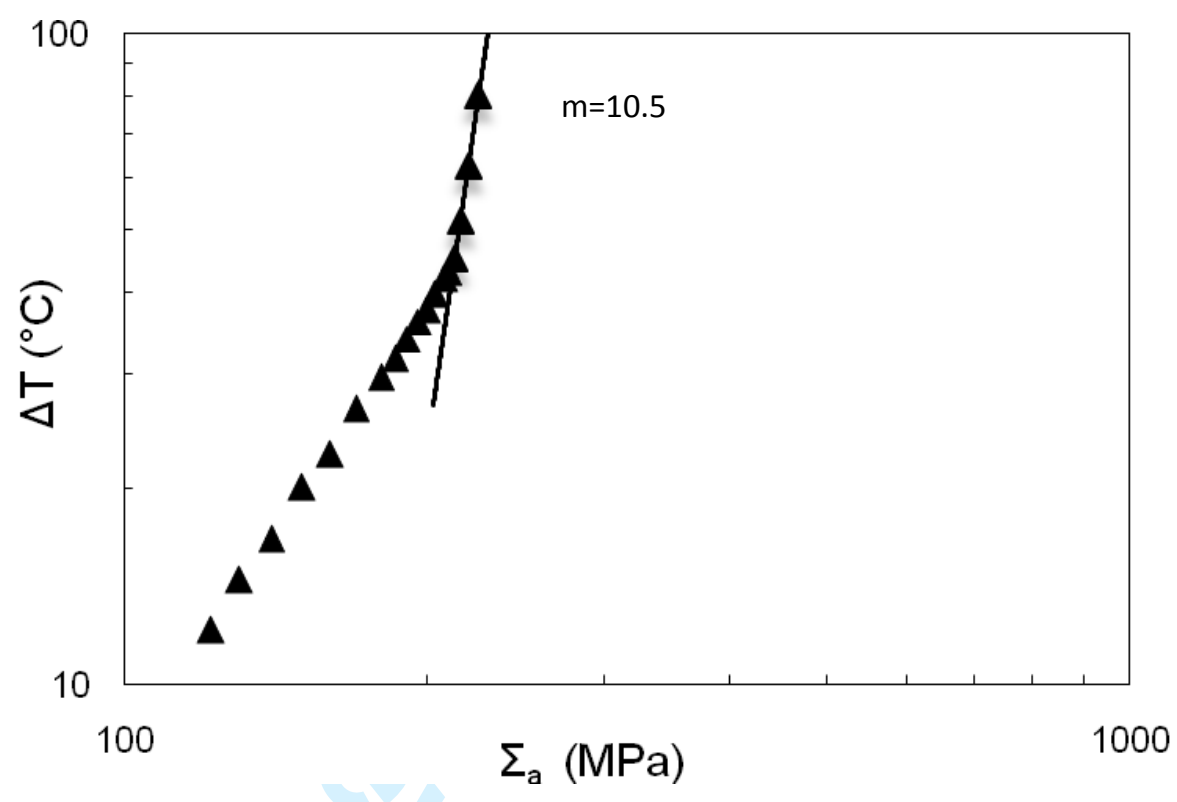

Figure 6 Bilinear relationships between incremental temperature and macro stress amplitude for low carbon steel in ultrasonic fatigue test 


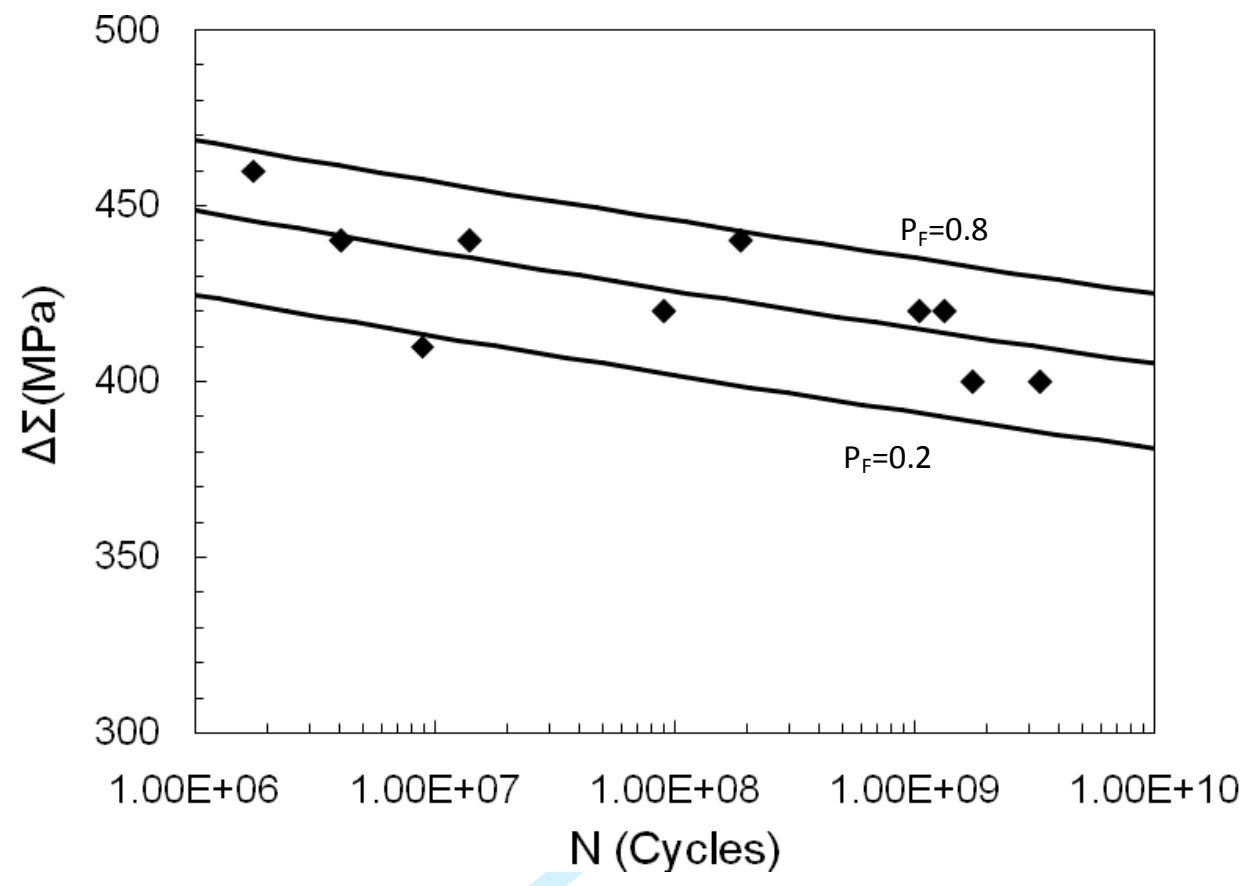

Figure 7 Predictiion of VHCF scatter for A42 steel 


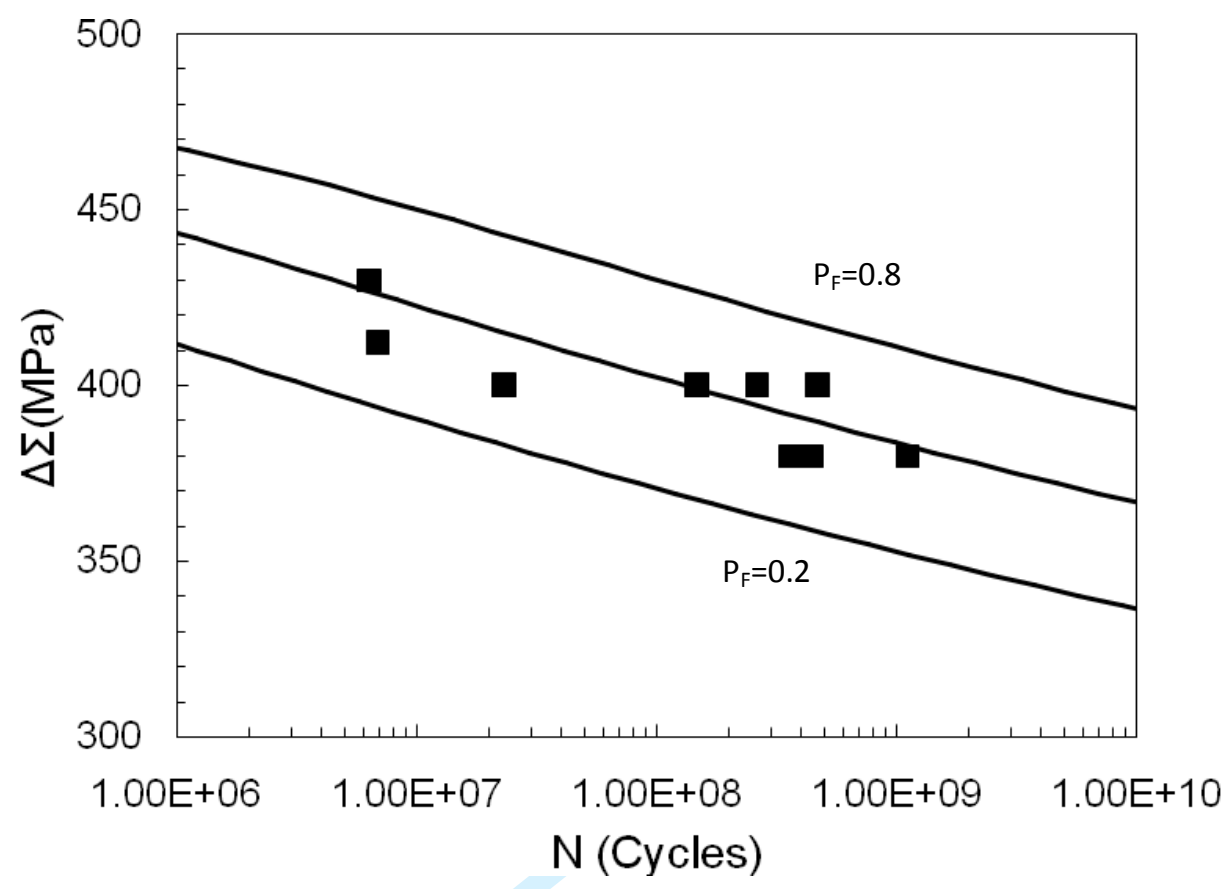

Figure 8 Prediting VHCF scatter for the spceimens pre damage by LCF for low $\mathrm{C}-\mathrm{Mn}$ steel (Points are for prior $0.62 \%$ strain amplitude, 100 cycles LCF damaged following VHCF test results) 
Table 1 Chemical composition of A48 and A42 steels, wt-\% (balance Fe)

\begin{tabular}{ccccccccc}
\hline Steel & $\mathrm{C}$ & $\mathrm{N}$ & $\mathrm{S}$ & $\mathrm{P}$ & $\mathrm{Si}$ & $\mathrm{Mn}$ & $\mathrm{Al}$ & $\mathrm{O}$ \\
\hline $\mathrm{A} 42$ & 0.140 & 0.0082 & 0.0057 & 0.016 & 0.225 & 0.989 & 0.045 & 0.0049 \\
\hline
\end{tabular}

Table 2 Material character of A42 and A48

\begin{tabular}{ccccc}
\hline Type of steel & $\begin{array}{c}\text { Elastic } \\
\text { Modulus } \\
\mathrm{E}(\mathrm{GPa})\end{array}$ & $\begin{array}{c}\text { Density } \\
\rho\left(\mathrm{kg} / \mathrm{m}^{3}\right)\end{array}$ & $\begin{array}{c}\text { UTS(MPa) } \\
\left(20^{\circ} \mathrm{C}\right)\end{array}$ & $\begin{array}{c}\text { Poisson } \\
\text { rate }\end{array}$ \\
\hline A42 & 209 & 7850 & $460 \mathrm{MPa}$ & 0.3 \\
\hline
\end{tabular}

